\title{
Environments for Healthy Aging: Linking Prevention Research and Public Health Practice
}

Rebecca H. Hunter, MEd; Lynda A. Anderson, PhD; Basia Belza, PhD, RN; Kristin Bodiford, PhD, MBA; Steven P. Hooker, PhD; Chris S. Kochtitzky, MSP; David X. Marquez, PhD; William A. Satariano, PhD, MPH

Suggested citation for this article: Hunter RH, Anderson LA, Belza B, Bodiford K, Hooker SP, Kochtitzky CS, et al. Environments for Healthy Aging: Linking Prevention Research and Public Health Practice. Prev Chronic Dis 2013;10:120244. DOI: http://dx.doi.org/10.5888/pcd10.120244 逢.

PEER REVIEWED

\section{Abstract}

Safe and well-designed community environments support healthful behaviors that help prevent chronic conditions and unintentional injuries and enable older adults to be active and engaged in community life for as long as possible. We describe the work of the Healthy Aging Research Network (HAN) and partners over the past decade to better understand place-based determinants of health and translate that knowledge to real-world practice, with a focus on environmental strategies. Using key components of the Knowledge to Action framework, we document the importance of a sustained, multidisciplinary, collaborative approach and ongoing interaction between researchers and communities. We share examples of practical tools and strategies designed to engage and support critical sectors with the potential to enhance the health and well-being of older adults and their communities. We conclude with a description of lessons learned in facilitating the translation of prevention research into practice.

\section{Introduction and the Knowledge to Action Framework}

Physical activity, social engagement, and a healthful diet help prevent chronic conditions and increase the longevity and quality of life of older adults (1-3). The importance of physical and social environments on human behavior and health is also well recognized. There are demonstrable cumulative environmental effects on the aging process and the health and functioning of older adults (4).

The United States will experience in the next 2 decades what has been described from a worldwide perspective as "one of the most daunting challenges of this century" - the unprecedented population growth, from 39 to 70 million, of people aged 65 or older (5). Corresponding growth in the number of older adults with disabling conditions can also be expected; in recent years, more than half of US adults aged 65 or older were reported to have 1 or more disabling conditions (6). Older adults vary in their susceptibility and exposure to unsafe or constraining environments, and those with chronic diseases or functional limitations may be even more adversely affected than their peers by environmental problems (7).

Practices and policies that support safe, age-sensitive, and fully accessible environments help ensure the healthiest possible aging and enable older adults to remain actively engaged in their communities. However, serious concerns exist about our preparedness to meet the challenges of population aging. According to the National Association of Area Agencies on Aging (n4a), in many US communities, "advancements are nowhere near the level of progress that has to be made to ensure that communities are livable for people of all ages" (8). The need to address such challenges underscores the urgency to translate prevention research into action and to define and test effective ways to reach key communities of practice, not only in public health but also in disciplines such as city planning, engineering, and architecture.

The Centers for Disease Control and Prevention's (CDC's) Healthy Aging Research Network (HAN) (www.cdc.gov/aging/han/index.htm), which works to better understand place-based determinants of healthy aging 
and translate findings into practice and policy, is well-positioned for such work. It has member centers from 7 US academic institutions, other university affiliates, and community, state, and national partners working to advance science toward action and policy in support of healthy aging (www.cdc.gov/aging/han/map.htm). HAN conducts research, develops and evaluates initiatives promoting healthy aging, and translates and disseminates science into sustainable, evidence-based public health programs and system-level strategies. HAN focuses on communities and populations that have a disproportionate prevalence of illness (9); consistent with US law, HAN does not use federal funds to directly or indirectly influence federal, state, or local legislation. HAN recognizes the importance of environmental facilitators and barriers to healthful behaviors and community engagement in the healthy aging process (9). Its work, as depicted in a modified Knowledge to Action framework (Figure) (10), reflects a distinct pattern of transition from applied research to translation, with the goal of informing practice and policy.

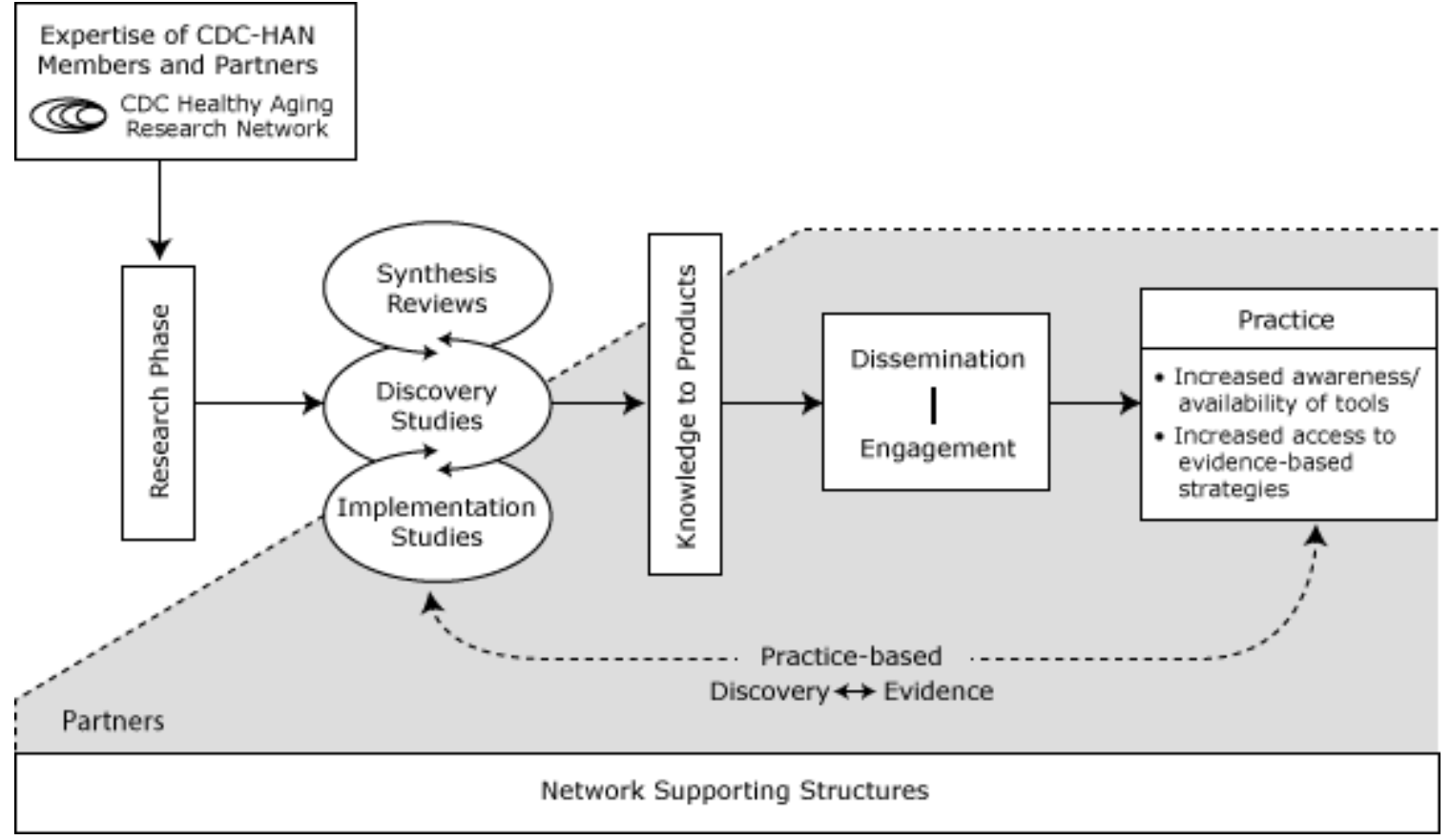

Figure. Healthy Aging Research Network Environmental Initiatives: Moving Knowledge to Practice. The HAN Environmental Initiatives Framework is based on the Knowledge to Action Framework (10), highlighting research, knowledge to products, dissemination, partner engagement, and practice effects. [A text description of this figure is also available.]

In this article, we use the framework to present the activities and lessons learned from a series of environmental initiatives conducted over 10 years. We briefly describe the network, including our members and partners, and the supporting structures that fund and help sustain our work. We then describe the development of a research agenda and select applied research activities related to synthesis reviews, discovery studies, and implementation studies. We next discuss how research activities led from knowledge to products and describe dissemination and engagement activities. We note the critical role of partners, many of whom are stakeholders with a long-term focus on healthy environments. Finally, we describe the effects of this work on practice, the ongoing influence of practice-based discovery and evidence on further research and dissemination, and the implications for future work.

\section{Supporting Structures and Partnerships}

Being part of an ongoing network has several advantages. First, CDC's Healthy Aging Program has provided core funding for HAN for more than a decade, allowing for member continuity and development of long-term working relationships. These factors undergird a shared longitudinal vision, support cross-site collaboration, and allow leveraging of resources. Second, network sites are widely distributed across the United States, from urban Seattle to rural South Carolina. These diverse locations represent a range of population groups and community characteristics. Moreover, HAN faculty and established partner organizations, such as the National Council on Aging and the National Association of Chronic Disease Directors, contribute interdisciplinary and cross-sector viewpoints essential for addressing environmental issues. Active community advisory boards anchor HAN sites, and their members provide real-world perspectives and ensure a strong connection to practice. Third, the network has an infrastructure for logistical support and communications through topical workgroups. Taken together, these provide continuity, strengthen capacity, and integrate accomplishments and lessons learned into new initiatives. 
Engaging external partners that share an environmental focus (eg, the US Environmental Protection Agency, Easter Seals) is pivotal to moving knowledge into action. Such organizations help frame issues from a national perspective and identify where and how HAN can best contribute. These collaborations result in more influence and expanded reach than are achievable by a sole entity.

\section{Research Phase}

In the research phase of the Knowledge to Action cycle, HAN builds evidence by synthesizing reviews of research findings and conducting discovery and implementation studies. To understand the science of environmental influences and healthy aging, we began more than 10 years ago to examine the literature, focusing on research that investigated environmental determinants of physical activity and looking for knowledge gaps and weaknesses from a public health context. We found a paucity of environmental measures that account for factors relevant for older adults, data pertaining to environmental influences on older adult health, and environmental interventions. These findings led us to conduct research activities related to the environment and older adult physical activity.

In a cross-site discovery study, we surveyed 2,110 community-based organizations in 2002 to determine physical activity program offerings and usage (11). Findings from the $77 \%$ of organizations that responded indicated that only $6 \%$ of local older adults participated in programs on at least a weekly basis; moreover, some programs such as strength training were not broadly available. Findings made available to study communities immediately influenced practice and program development. A searchable online database tool, Active Options, was subsequently launched to provide access to information about available physical activity programs to older adults and service providers and to facilitate community planning.

Given the demonstrated need for an age- and disability-sensitive built environment measure, we developed the HAN Environmental Audit Tool in 2005 to assess the safety, walkability, and ease of navigation of the built environment for older pedestrians and to ascertain features of the built environment that are important to mobility (12). The Environmental Audit Tool is an adaptation of an existing instrument (13) that was developed on the basis of findings from a discovery study series of older adult interviews and community-based pilot studies across HAN sites. We continue to refine the tool based on new research findings and feedback from other researchers and community users.

The physical activity programs survey and HAN audit tool projects, conducted in geographically diverse HAN sites, showed differences in community environments, particularly between those that were rural and urban. These lessons led us to study types of communities through related initiatives including a review of the effects of the rural built environment on adult physical activity (14), a review on the food environment (15), and audit tool revisions to address rural environment features. We further committed to consider site diversity in subsequent HAN research.

The Robert Wood Johnson Foundation provided funding to 4 HAN sites for a cross-sectional study of 884 people aged 65 or older from diverse communities, assessing how characteristics of the built environment affect older adult patterns of walking and other forms of physical activity. Individual interviews, physical performance measures, and accelerometer data obtained between 2005 and 2007 were complemented by objective environmental measures. Findings indicated the importance of key relationships; for example, living in a residential area, compared with a mixed-use or commercial area, is associated with less time spent walking (16). Older adults with reduced cognitive function were more likely to walk indoors than those with higher functional levels (17), and perceived crime and reduced access to services were associated with higher body mass index (18). Results enhanced understanding of other factors (eg, self-efficacy for walking is linked to reduction or delay of functional limitations [19]) and provided a broader research agenda on mobility.

The National Highway Traffic Safety Administration provided core funding to the University of North Carolina Highway Safety Research Center for Walk Wise, Drive Smart (www.walk-wise.org/), an implementation study conducted in cooperation with the City of Hendersonville, North Carolina. We assessed walking conditions in 10 neighborhoods using the HAN Environmental Audit Tool and resident feedback. These data indicated need for improvement of pedestrian facilities to reduce hazards and barriers to walking by older adults and the need for changes in driver behavior and walking programs tailored to adults with varying fitness levels. The intervention included community education, law enforcement, encouragement of walking, and environmental assessment and modification, including physical improvements to selected routes to improve safety and walkability. The effectiveness of public health professionals, city officials, and informed citizens in making needed environmental changes was a key lesson in the power of cross-sector collaboration.

\section{Knowledge to Products and Practice Effects}

Establishing relationships with communities during our research indicated the need for greater attention to change in environmental practice and policy to broadly affect public health. To move from knowledge to products and practice, we learned to seek out professionals from diverse disciplines who were leaders in environmental and policy change 
(20) and to engage them in establishing priorities and effective practices. Accordingly, we conducted a research-topractice symposium, focusing on the challenges of environmental and policy change, the evidence for specific approaches, and promising strategies for practice (5). Conducted in collaboration with the CDC Healthy Communities Program and other sponsors such as AARP and the YMCA, the symposium engaged more than 150 leaders from public health, aging, architecture, business, planning, engineering, recreation, and health care. As a result of the conference, $60 \%$ of attendees planned to address their communities' issues and to initiate programs and practices. Participants identified areas that they would work on, including environmental improvement strategies in their states and communities, and advised us to continue to foster cross-sector collaboration.

Follow-up dissemination activities included presentations to diverse stakeholder groups and a manuscript articulating strategies for improvements in environmentally relevant aging strategies during the second decade of the 21st century (21). With support from the Agency for Healthcare Research and Quality, we began an initiative to engage and support additional professionals from diverse disciplines in planning and implementing environmental strategies. In collaboration with Creating Aging Friendly Communities (CAFC) (http://agingfriendly.org/), an Internet community of more than 2,700 participants worldwide, we conducted an online conference series including interactive webinars, on-demand presentations, and selected resources, and facilitated technical support activities. The series brought together researchers, decision makers, and practitioners to advance the implementation of strategies proven to improve public health outcomes. The initiative had excellent reach; 1,206 participants made 4,123 visits to the conference website. Most importantly, participants reported taking steps likely to lead to environmental improvement $(55 \%)$ and seeing results from those steps (35\%). Online resources remain accessible at CAFC.

This interactive dissemination allowed for incorporation of practice-based discovery, yielding fresh insights, increasing understanding of complex practice and policy issues, identifying promising practices, and defining additional areas with potential for impact. As a result, CDC provided support to develop the Environmental and Policy Change Clearinghouse, a searchable, annotated database of online materials about healthy aging and environmental and mobility issues (www.epc-clearinghouse.org.). Recipient of a 2011 APEX Award for Excellence in Publication the clearinghouse includes 130 selected resources and can be readily expanded to include other topics, thereby increasing public access to useful tools and evidence-based strategies. The site had more than 669 visits in its inaugural 3 months.

Follow-up outreach included the public health and aging communities but also extended to key stakeholders (eg, planners, city engineers) via participation in meetings such as New Partners for Smart Growth and ProWalk/ProBike. In these meetings, we highlighted priorities for environmental improvement in areas with potential for high impact, including age- and disability-sensitive neighborhood design and safety, accessible housing stock to support aging in community, fully coordinated mobility and transportation options, and integration of environmental hazard protection into all planning. We also created a series of action briefs (www.prc-han.org/tools-environment\#envbriefs) on these issues and broadly disseminated them via partnering organizations. The series, entitled Optimal Living, includes 4 topics: Frameworks to Guide Change, Promising Strategies, Getting Around (focused on mobility), and Home Environments. The briefs focus on promising environmental change strategies for the decade and are intended to inform practitioners and decision-makers in different fields.

Overall, dissemination and engagement efforts have drawn attention to aging-related environmental issues in fields such as urban planning and engineering and in other areas such as falls prevention. For example, the North Carolina Falls Prevention Coalition, in collaboration with public health professionals and city planners, has included neighborhood falls risk assessments into their approach for falls prevention. Other examples are found on the HAN website (www.prc-han.org).

\section{Knowledge to Action and Back Again}

HAN's environmentally oriented work has been cyclical; each phase in the Knowledge to Action framework informs the next steps. Major concept development initiatives are under way to synthesize knowledge across disciplines in 2 understudied areas: older adult mobility and community wayfinding. Mobility, including both active and passive transportation, and wayfinding, including the system of environmental cues to support mobility, are vital to health and community engagement throughout the lifespan. In support of these initiatives, we are also conducting a study of community wayfinding in Chicago, combining use of the HAN Environmental Audit Tool with older adult interviews and neighborhood wayfinding tasks.

For more than a decade, HAN has moved science to practice to promote environments for healthy aging. Our experience illustrates the potential of a network of strong member centers and an evolving network of partners with varying missions to achieve common goals. We look forward to continuing to address the challenges of an aging society, helping ensure that our work contributes to the healthiest possible society for all. 


\section{Acknowledgments}

This article is the result of work conducted by the CDC HAN, a Prevention Research Centers thematic network funded by the CDC Healthy Aging Program. Efforts were supported in part by cooperative agreements from CDC's Prevention Research Centers Program nos. U48-DP-001911, 001908, 001921, 001924, 001936, 001938, and 001944. We express gratitude to James LoGerfo, MD, MPH, who guided the development of HAN in its early years and who set the stage for this work. We also thank Gwen Moni, manager of the HAN Coordinating Center since its inception and a steadfast contributor to all of our work.

\section{Author Information}

Corresponding Author: Rebecca H. Hunter, University of North Carolina, Center for Health Promotion and Disease Prevention, 228 Indian Trail Rd, Chapel Hill, NC 27514. Telephone: 919-260-0175. E-mail: Rebecca_Hunter@unc.edu.

Lynda A. Anderson, Centers for Disease Control and Prevention and Emory University, Atlanta, Georgia; Basia Belza, University of Washington, Seattle, Washington; Kristin Bodiford, Community Strengths, Alamo, California; Steven P. Hooker, Arizona State University, Phoenix, Arizona; Chris S. Kochtitzky, Centers for Disease Control and Prevention, Atlanta, Georgia; David X. Marquez, University of Illinois at Chicago, Chicago, Illinois; William A. Satariano, University of California, Berkeley, Berkeley, California.

\section{References}

1. Seguin R, Lamonte M, Tinker L, Liu J, Woods N, Michael YL, et al. Sedentary behavior and physical function decline in older women: findings from the Women's Health Initiative. J Aging Res 2012;2012:271589. PubMed 通

2. Thomas PA. Trajectories of social engagement and mortality in late life. J Aging Health 2012;24(4):547-68. CrossRef 通 PubMed 虔

3. Peel NM, McClure RJ, Bartlett HP. Behavioral determinants of healthy aging. Am J Prev Med 2005;28(3):298304. CrossRef is PubMed 图

4. Stein J, Schettler T, Roher B, Valenti M. Environmental threats to healthy aging. Boston (MA): Greater Boston Physicians for Social Responsibility and Science and Environmental Health Network; 2008.

5. Managing the global ageing transition: a center for strategic and international studies conference. Zurich $(\mathrm{CH})$ : Centre for Global Dialogue; 2001. p. 2.

6. Brault M. Americans with disability: 2005, current population reports. US Census Bureau; 2008. http://www.census.gov/prod/2008pubs/p70-117.pdf. Accessed July 6, 2012.

7. Theis KA, Furner SE. Shut-in? Impact of chronic conditions on community participation restriction among older adults. J Aging Res 2011;2011:759158. PubMed 圈

8. The maturing of America - communities moving forward for an aging population. National Association of Area Agencies on Aging; June 2011. http://www.n4a.org/files/MOA_FINAL_Rpt.pdf. Accessed July 6, 2012.

9. The Healthy Aging Research Network Writing Group. The Prevention Research Centers Healthy Aging Research Network. Prev Chronic Dis 2006;3(1):A17http://www.cdc.gov/pcd/issues/2006/jan/o5_0054.htmAccessed July 19, 2012. PubMed 图

10. Wilson KM, Brady TJ, Lesesne C; NCCDPHP Work Group on Translation. An organizing framework for translation in public health: the Knowledge to Action Framework. Prev Chronic Dis 2011;8 (2):A46http://www.cdc.gov/pcd/issues/2011/mar/10_0012.htmAccessed July 6, 2012. PubMed 虑

11. Hughes SL, Williams B, Molina LC, Bayles C, Bryant L, Harris J, et al. Characteristics of physical activity programs for older adults: results of a multisite survey. Gerontologist 2005;45(5):700-4. CrossRef F $^{*}$

12. Kealey M, Kruger J, Hunter R, Ivey S, Satariano W, Bayles C, et al. Engaging older adults to be more active where they live: audit tool development. Prev Chronic Dis 2005;2(2). http://www.cdc.gov/pcd/issues/2005/apr/o4_0142q.htmAccessed July 5, 2012.

13. Brownson R, Hoehner C, Brennan Ramirez LK, Cook RA, Elliott MB, McMullen KM. Reliability of two instruments for auditing the environment for physical activity. J Phys Act Health 2004;1:191-208.

14. Frost SS, Goins RT, Hunter RH, Hooker SP, Bryant LL, Kruger J, et al. Effects of the built environment on physical activity of adults living in rural settings: a review of the literature. Am J Health Promot 2010;24(4):26783. CrossRef 图 PubMed 图

15. Sharkey JR, Horel S. Neighborhood socioeconomic deprivation and minority composition are associated with better potential spatial access to the ground-truthed food environment in a large rural area. J Nutr 2008;138 (3):620-7. PubMed 迹 
Preventing Chronic Disease I Environments for Healthy Aging: Linking Prevention Resea... Page 6 of 6

16. Satariano WA, Ivey SL, Kurtovich E, Kealey M, Hubbard AE, Bayles CM, et al. Lower-body function, neighborhoods, and walking in an older population. Am J Prev Med 2010;38(4):419-28. CrossRef 图 PubMed 虚

17. Prohaska TR, Eisenstein AR, Satariano WA, Hunter R, Bayles CM, Kurtovich E, et al. Walking and the preservation of cognitive function in older populations. Gerontologist 2009;49(Suppl 1):S86-93. CrossRef 浨 PubMed 逐

18. Eisenstein AR, Prohaska TR, Kruger J, Satariano WA, Hooker S, Buchner D, et al. Environmental correlates of overweight and obesity in community-residing older adults. J Aging Health 2011;23(6):994-1009. CrossRef PubMed 逢

19. Mullen SP, MacAuley E, Satariano WA, Kealey M, Prohaska TR. Physical activity and functional limitations in older adults: the influence of self-efficacy and functional performance. J Gerontol B Psychol Sci Soc Sci 2012;67 (3):354-61. CrossRef is PubMed 图

20. Kochtitzky CS, Freeland AL, Yen IH. Ensuring mobility-supporting environments for an aging population: critical actors and collaborations. J Aging Res 2011;2011:138931. PubMed 迹

21. Hunter RH, Sykes K, Lowman SG, Duncan R, Satariano WA, Belza B. Environmental and policy change to support healthy aging. J Aging Soc Policy 2011;23(4):354-71. CrossRef 图 PubMed 图

The opinions expressed by authors contributing to this journal do not necessarily reflect the opinions of the U.S. Department of Health and Human Services, the Public Health Service, the Centers for Disease Control and Prevention, or the authors' affiliated institutions.

The RIS file format is a text file containing bibliographic citations. These files are best suited for import into bibliographic management applications such as EndNote $\mathbf{F}^{\mathrm{N}}$, Reference Manager download is available at each application's web site.

For Questions About This Article Contact pcdeditor@cdc.gov

Page last reviewed: April 18, 2013

Page last updated: April 18, 2013

Content source: National Center for Chronic Disease Prevention and Health Promotion

Centers for Disease Control and Prevention 1600 Clifton Rd. Atlanta, GA 30333, USA

8oo-CDC-INFO (80o-232-4636) TTY: (888) 232-6348 - Contact CDC-INFO 